\title{
Soares, Tânia de Morais (2006) Cibermedi@ - Os meios de comunicação social portugueses online, Lisboa: Escolar Editora
}

Daniela Bertocchi*

A leitura de Cibermedi@ - Os meios de comunicação social portugueses online, obra da socióloga e investigadora portuguesa Tânia de Morais Soares, que propomos aqui para um breve recenseamento, fornece-nos dados capazes de nos ajudar a desenhar respostas às questões: Como foi que os meios de comunicação social tradicionais portugueses - ou seja, emissoras de televisão, de rádio e a imprensa escrita - se apropriaram do espaço digital, nomeadamente da Internet, nos últimos anos? Como o fizeram e, mais do que isso, que objectivos e estratégias adoptaram?

Cibermedi@ apresenta um rigoroso estudo que analisa 25 meios de comunicação portugueses (em imprensa escrita, rádio e televisão) existentes em suporte físico tradicional, todos de expansão nacional, tendencialmente generalistas e que possuem uma presença na Internet ${ }^{1}$. Os resultados da pesquisa estão circunscritos ao período que vai de 1998 até $2003^{2}$.

A pesquisa sugere que os meios de comunicação social portugueses com páginas web evoluíram neste período. Se antes os primeiros registos online tiveram apenas o intuito de "marcar presença" na Internet, nos últimos anos verificaram-se investimentos sérios no aprofundamento de conteúdos informativos e na prestação de serviços. Os sites dos meios de comunicação também promoveram mudanças positivas em termos de organização, aspecto gráfico e estrutura dos seus conteúdos.

Nesta visão evolutiva bastante positiva, a autora da pesquisa afirma ainda que os media portugueses tomaram consciência da necessidade de promover espaços de interactividade entre os emissores da informação e os seus consumidores. Igualmente, os responsáveis pelas páginas web dos media tradicionais perceberam as vantagens da disponibilização de arquivos de informação (e edições anteriores) aos leitores dos seus sites.

A percepção do quadro evolutivo dos media portugueses com presença na Internet dá-se a partir de um conjunto de indicadores quantitativos e qualitativos agregados pela autora em grandes categorias analíticas. Tentaremos aqui apresentar e comentar, de forma resumida, em 15 pontos, os principais indicadores apresentados no estudo ${ }^{3}$ :

\footnotetext{
* Daniela Bertocchi é pesquisadora do Projecto Mediascópio/Ciberlab (danielabertocchi@gmail.com http://bertocchi.info).

${ }^{1}$ Entre eles encontramos sete jornais (como Público, Diário de Notícias e Correio da Manhãa, entre outros); três emissoras televisivas (RTP, TVI, SIC); uma revista (Visão Online) e doze emissoras de rádio - como Rádio Comercial, RDP (Antenas 1, 2 e 3), TSF, Rádio Cidade e Rádio Renascença, entre outras. Embora a pesquisa se centre nos media tradicionais com presença na web, a autora acaba optando por agregar à amostra dois registos de media existentes apenas em suporte online: os jornais Portugal Diário e Diário Digital.

${ }^{2}$ A pesquisa desenvolveu-se como dissertação de mestrado da autora entre os anos de 2002 e 2003 no ISCTE, mas engloba explorações realizadas anteriormente entre 1998 e 2000 pelo Projecto Ciberfaces: Internet, Interfaces do Social.

${ }^{3}$ Optamos por expor os dados apresentados na quarta parte da obra, aquela que constitui, nas palavras da própria autora, e que certamente corroboramos, a vertente mais actual e original de sua pesquisa.
} 
1. Em primeiro lugar, a pesquisa revela que se tem tornado mais fácil para os usuários aceder às páginas web dos meios de comunicação portugueses. Praticamente todas as páginas analisadas estão operacionais (96\%), e não em "reconstrução" (4\%). Boa parte também pode ser visualizada de forma rápida e sem problemas (80\%). As páginas mantêm os seus conteúdos bem organizados e com uma navegação hipertextual intuitiva $(66,7 \%)$, segundo uma análise subjectiva da autora. Mas, para aceder à totalidade das informações, os internautas precisam, cada vez mais, de fornecer os seus dados pessoais ao meio de comunicação em causa. A lógica que se está a instaurar nos media portugueses é a de que "um bom utilizador é um utilizador registado". Mais de metade dos sites dos media portugueses $(62,5 \%)$ exigem que o usuário forneça os seus dados pessoais para aceder a conteúdos e serviços específicos (boletins informativos, fóruns, chats, versão em PDF das edições offline etc.). E 16,7\% destes sites cobram aos usuários o acesso a tais conteúdos e serviços.

2. A investigadora observa que os media tradicionais portugueses com presença na web passaram a dar mais importância ao armazenamento de informação. Os arquivos documentais foram encontrados em $66,7 \%$ das páginas analisadas $(41,7 \%$ destes são considerados pela autora "bem interessantes" e $25 \%$ "arquivos precários”).

3. O serviço de emissão em directo e/ou a disponibilização da edição do dia está presente em $87,5 \%$ dos sites da amostra. O meio da rádio parece ser o principal responsável pela elevada percentagem geral: todos os sites de rádio online analisados possuem emissão em directo e em tempo real. As páginas das televisões são as que menos exploram esse recurso, embora forneçam vídeos on demand. Os jornais impressos mantêm-se na lógica de texto e imagem estática (para conteúdos exclusivos online ou advindos do offline), mesmo pertencendo a grandes grupos mediáticos e, teoricamente, oferecem a possibilidade de fazer o download de vídeos ou áudios.

4. Os responsáveis pelas páginas web dos media parecem ter cada vez mais consciência da importância de se criar uma interface com o utilizador que lhe confira a sensação de poder interagir com os conteúdos e os emissores destes conteúdos. Consciência que tem a ver com uma estratégia de fidelização deste público. Do total da amostra, 58,3\% das páginas web possuem um espaço destinado a opiniões e comentários de usuários. De acordo com a análise qualitativa da autora, os jornais e televisões online são os que mais exploram as possibilidades de interacção, permitindo ao usuário imprimir, enviar ou comentar as notícias e artigos disponibilizados. Em alguns casos, afirma a investigadora, chegam a dar destaque aos comentários dos usuários, conferindo-lhes quase que um prémio de excelência ao dar notoriedade à expressão do utilizador comum. Mais à frente na pesquisa, no item sobre a identidade assumida pelos media online, a autora irá revelar que $62,5 \%$ das páginas analisadas recorrem a utensílios tecnológicos (não apenas para comentário) que favorecem a interacção entre o meio e o público, embora não fique claro na pesquisa que ferramentas são essas e que tipo de interactividade podem proporcionar. Entretanto, aponta também que um número considerável de sites $(37,5 \%)$ tende a desprezar a possibilidade de interacção, permanecendo naquilo que a socióloga chama uma "lógica panfletária” de apenas marcar presença na web. 
5. A actividade mediática portuguesa online ainda não é lucrativa e tem procurado a sua sustentabilidade através da publicidade online, na sequência daquilo que já é prática corrente no financiamento dos media privados. Embora a pesquisa não se aprofunde numa análise do cenário económico dos sites mediáticos, ainda assim consegue revelar, a partir da análise de conteúdo, que $83,4 \%$ das páginas analisadas apresentam publicidade, sendo que, deste total, 41,7\% o fazem de forma abundante. Não raro, são anúncios que aparecem com grande destaque nas páginas de entradas dos sites e que apelam sucessivamente à visita do usuário. Boa parte dos anúncios é generalista $(75 \%)$. As páginas que não apresentam nenhum tipo de publicidade $(16,7 \%)$ são essencialmente as correspondentes aos media públicos financiados pelo Estado. É de destacar, entretanto, que 54,5\% das páginas analisadas parece conseguir fontes de receita a partir de ligações com portais web (IOL, Sapo etc.), classificados e publicidade externa e que $18,2 \%$ da amostra total sobrevive de subsídios. A maioria das páginas mediáticas analisadas não fornece a possibilidade de transacções online, mas apenas de obter informações comerciais para que os negócios se realizem offline.

6. A autora observa que os diferentes tipos de media online portugueses de expansão nacional tendem a assumir uma organização e uma lógica de apresentação na Internet similar e onde domina o formato mais próximo da identidade da imprensa escrita. Os sites das rádios são os que mais se distinguem dos outros na forma como se apresentam na Internet, devido sobretudo ao tipo de conteúdo definido para o offline. Mas, à excepção das páginas do meio rádio, todas as outras se aproximam da lógica de gestão e organização da informação baseada no modelo clássico dos jornais: textos e imagens estáticas. Em suporte online, a pesquisa revela portanto que as páginas de televisão e de jornais se aproximam no que respeita a este indicador e que, contrariamente ao mundo offline, são os jornais que parecem ditar as regras na forma de apresentação de conteúdos online.

7. Foram identificadas pela socióloga três vertentes ou funções registadas nas páginas analisadas: informativa, de entretenimento e comercial. A vertente comercial da Internet parece estar a ser intensamente contemplada pelos media portugueses. Numa hierarquização da autora, teríamos as vertentes nesta ordem: em primeiro lugar, a função comercial (forte em 54,2\% das páginas); em segundo lugar, a função informativa (presente enfaticamente em $41,7 \%$ da amostra); e, por último, a função de entretenimento (significativa em $37,5 \%$ dos sites analisados). A pesquisa revela que a televisão e imprensa escrita online apostam mais determinadamente na vertente informativa e comercial da Internet, enquanto as rádios apostam mais no binómio entretenimento/ comércio, salientando os conteúdos com tais características.

8. Ainda ao nível dos conteúdos, a pesquisa aponta que os sites dos media portugueses permanecem numa lógica de aproveitamento de conteúdos produzidos para o suporte tradicional no novo suporte digital, o que remeteria para a necessidade de incentivar a produção de conteúdos específicos para o novo ambiente.

9. Neste sentido, boa parte dos conteúdos em destaque nas páginas analisadas acabam por ser naturalmente auto-promocionais $(22,2 \%)$, ou seja, destacam produtos 
do meio em causa. No caso das televisões e das rádios, trata-se de destacar e autopromover os seus programas (de entretenimento ou de informação), as personalidades e vedetas da estação. No caso dos jornais, trata-se de destacar e rentabilizar os conteúdos da edição impressa. Depois dos conteúdos auto-promocionais, o que mais aparece em destaque são as "últimas informações" $(20,4 \%)$, que correspondem à actualidade informativa no caso dos jornais e televisões e dizem respeito às últimas novidades da música e dos espectáculos na maioria dos sites das rádio. Em terceiro lugar neste ranking de destaques, encontram-se os conteúdos que têm a ver com produtos ou serviços de empresas ou de outros media pertencentes ao mesmo grupo económico $(18,5 \%)$. Dentre os destaques, há $12 \%$ deles ligados de alguma forma à publicidade, outros $12 \%$ aos portais temáticos e $9,3 \%$ aos portais generalistas e $5,6 \%$ são destaques de sites de turismo. Os dados sobre os destaques revelam, conforme expõe a autora, que a lógica de funcionamento como grupo económico influencia o peso do destaque conferido aos portais em geral que, quer sejam do âmbito temático ou generalista, tendem a ter a mesma propriedade que a página em causa. Isto explica também a estreita relação de convivência de inúmeras páginas de media portugueses com portais generalistas e temáticos, que chegam por vezes a confundirem-se, não sendo fácil discernir que conteúdos são do meio de comunicação em causa e quais são do portal. É de salientar que o portal IOL e Sapo funcionam como "site âncora" respectivamente de $28 \%$ e $12 \%$ do total de sites da amostra. No item da pesquisa sobre a identidade assumida pelos media online, isso é reafirmado pela investigadora: 79,1\% das páginas web dos media portugueses funcionam de facto segundo uma lógica de grupo económico, integrando na mesma página ligações às diferentes empresas do grupo e criando sinergias entre os conteúdos dos diferentes media rentabilizando-os no novo meio Internet.

10. A lógica de grupo económico e a estreita relação dos media com os portais também se torna evidente a partir da observação dos tipos de links externos mais visíveis nas páginas dos media portugueses. Do total de links externos identificados pela pesquisadora, aparecem em grande destaque os que procuram enviar o usuário para páginas de empresas ou conteúdos do mesmo grupo ou propriedade, mesmo que de diferente suporte $(14,2 \%)$. Também abundantes são os links externos para anúncios e classificados $(10,8 \%)$ e para portais temáticos $(9,5 \%)$ e generalistas $(6,8 \%)$. Em menor destaque, encontram-se os links que remetem para as páginas de medias estrangeiros $(3,4 \%)$, estes presentes somente em sites de jornais e totalmente desprezados pelos sites de televisões e rádios.

11. A autora afirma que existe um conjunto significativo de páginas de televisão, rádio e jornal portugueses com um elevado número de informação e uma grande diversidade de conteúdo $(58,3 \%)$. Mas quase metade da amostra (41,7\%) revela ainda uma grande inconsistência em termos de volume e diversidade informativos. Entre as páginas menos consistentes, encontram-se sobretudo as do meio rádio. Segundo a pesquisadora, porque boa parte dos sites de rádio perdeu a sua lógica de meio generalista (rádios vocacionadas para a dimensão informativa) para se inscrever na lógica de meio temático (rádios vocacionadas exclusivamente para o mundo da música e dos espetáculos). 
12. Do total da amostra analisada, metade tem actualização de conteúdo constante $(50 \%)$. Entre esses, destacam-se os sites dos jornais e televisões. Há páginas actualizadas somente diariamente $(16,7 \%)$ ou semanalmente $(8,3 \%)$, mas note-se que $25 \%$ das páginas da amostra tem uma actualização não identificável. Novamente são as páginas do meio rádio que destoam do quadro geral: por serem menos direccionadas para a actualidade noticiosa e mais voltadas para a programação musical, acabam conduzindo a uma menor necessidade de actualização de conteúdos.

13. De um modo geral, uma boa parte dos sites dos media portugueses tem mais um perfil popular $(41,7 \%)$ do que um perfil generalista $(33,3 \%)$. A minoria dos media online analisados é considerada de perfil elitista (25\%). As páginas das televisões são as que apresentam um perfil mais generalista (dirigem-se a todo o tipo de público e enquadram uma grande variedade temática), enquanto as rádios online são consideradas as mais populares (enveredam por conteúdos mais consensuais, simplistas e apelativos). Os jornais online são os mais elitistas, no sentido em que se baseiam em conteúdos ou em formas de tratamento da informação mais aprofundados e contextualizados dirigidos a interesses e públicos específicos.

14. Naturalmente, acaba por haver uma predominância de informações fragmentadas e efémeras $(54,2 \%)$ em detrimento de informações contextualizadas e aprofundadas $(45,8 \%)$. Os sites das televisões e rádios primam mais pelos conteúdos do primeiro tipo, enquanto os sites dos jornais, contrariamente, tal como no suporte tradicional, tendem a contextualizar mais a informação e tratá-la de forma mais aprofundada.

15. A autora identifica a existência de duas lógicas internas fundamentais que se destacam entre as páginas analisadas: primeiramente, a que predomina e que encara cada página como integrante de um todo, onde as diferentes empresas do mesmo grupo marcam a sua presença e favorecem a navegação pela totalidade das empresas ou media com a mesma propriedade $(54 \%)$; e, de uma forma distinta, as páginas autocentradas $(46 \%)$, ou seja, que aplicam todos os seus esforços em se promoverem a si próprias, destacarem as suas qualidades e fidelizar o público da web em seu torno. Igualmente, a autora identificou uma lógica geral de construção de páginas: constatase uma tendência para a hibridez entre aquilo que é uma presença típica de um meio de comunicação na web (com conteúdos, organização e funcionamento específico de um meio em causa) e o que seria uma porta de acesso à Internet (página que direcciona o usuário para conteúdos diversos).

Um primeiro comentário que podemos tecer diante dos dados seleccionados é em relação àquilo que diz respeito particularmente aos media portugueses online e o que pode ser identificado como sendo um movimento mais amplo e global. Apesar de a pesquisa não ter o compromisso de comparar os media de várias regiões geográficas, vale a pena notar que em relação à performance de acesso (que englobaria dificuldades como demasiado tempo de espera para carregar uma página, altos custos de utilização, etc.), ao acesso restrito aos conteúdos e serviços (tanto gratuito como pago), e mesmo em relação ao predomínio do formato da imprensa escrita e à busca da participação 
do usuário, observamos que estes fenómenos formam, na verdade, uma tendência não necessariamente exclusiva da realidade portuguesa; são fenómenos igualmente verificáveis noutros media online estrangeiros, europeus ${ }^{4}$ e não só.

Observamos também que certos dados apontados pela pesquisa mereceriam estudos específicos aprofundados para conseguirmos chegar a conclusões mais objectivas. $\mathrm{Na}$ questão do armazenamento da informação, por exemplo, não fica claro até que ponto a recuperação de dados por parte do usuário efectivamente funciona: fornecer um banco de dados completo e actualizado não significa obrigatoriamente que o usuário irá encontrar o que deseja e da forma que deseja. O mesmo vale para a composição hipertextual dos conteúdos informativos, visivelmente inadequada quando se faz a mera transposição de conteúdos offline para o meio online. À semelhança disto, é necessária uma pesquisa mais específica no que diz respeito aos modos de sustentabilidade financeira dos sites mediáticos portugueses, ou, melhor ainda, saber em que modelos de negócio têm apostado nos últimos anos, que derrapagens têm sofrido e que estratégias têm funcionado - sugestão de aprofundamento indicada pela própria autora e que aproveitamos para reiterar.

Em terceiro lugar, o ponto que aqui julgamos o mais relevante: a partir dos variados e consistentes dados apresentados em Cibermedi@, e já inevitavelmente pensando no caminho que têm percorrido os media online após o período da realização da pesquisa, somos levados a dizer que os meios de comunicação social tradicionais portugueses com presença na web ainda precisam de encontrar uma resposta a uma questão essencialmente existencial: o que são e qual a sua missão neste mundo. Configuram-se como uma réplica dos meios offline, encaram o meio online como mero apoio difusionista do offline, entendem-se como vitrinas auto-promocionais ou ainda como amplos portais de acesso à web, ou buscam efectivamente alcançar uma lógica de comunicação digital?

Se optam pelo último caminho, a visão evolutiva do período pode ser menos optimista: os media portugueses tradicionais precisam obrigatoriamente de investir mais na criação de conteúdos informativos para as suas páginas online, integrando-os dinamicamente de forma multimediática (o que, inclusive, não agride a lógica vigente de grupo económico); perceber de facto o que é e qual a função da interactividade entre meios de comunicação e públicos online; e, sobretudo, prestar uma maior atenção às tecnologias e aos fenómenos ciberculturais emergentes (RSS, weblog, podcast, videocast, etc.), ainda timidamente explorados no cenário mediático português.

Ao traçar de modo sistemático grandes linhas de força e tendências sobre os media online portugueses, Cibermedi@ não se limita a deixar esta boa pista a seguir, como se torna ainda referência fundamental para desvelarmos, nos próximos anos, como este cenário evoluirá em Portugal.

${ }^{4}$ Ver Salaverría, R. (coord.) (2005) Cibermedios. El impacto de internet en los medios de comunicación en España, Sevilla: Comunicación Social Ediciones y Publicaciones. 